\title{
Irrigation Practices and Intestinal Helminth Infections in Southern and Central Zones of Tigray
}

\author{
Tadesse Dejenie and Beyene Petros
}

\begin{abstract}
Background: Irrigation practices have impact on the distribution of schistosomiasis; so, identifying newly established schistosomiasis transmission foci allows for designing prevention and control strategy.

Objective: To establish schistosomiasis prevalence and intensity in relation to development of water bodies for irrigation.

Methods: A survey of stool specimens of 2000 school children using Kato thick smear method was carried out in Central and Southern Tigray between October 2001 and January 2002.

Results: Among the 1012 males and 998 females examined, 29\% males and 27.5\% females were found positive for one or more parasite. The prevalence of $S$. mansoni was $27 \%$ in longstanding irrigated, $10.8 \%$ in recently constructed irrigation schemes and $1.8 \%$ in the non-irrigated rural localities. In the urban setting, its prevalence was $15.5 \%$ in areas with water body nearby and $0.5 \%$ in areas with no water body nearby $(\mathrm{P}<0.0001)$. New $S$. mansoni infection foci were detected in Tumuga with a prevalence of 87\%; Dibdibo (41\%), Mariam Shewito (25\%), Adiha (23\%) and Lekia (9\%).

Conclusion: The increasing risk of schistosomiasis mansoni in the irrigation sites is high. Hence, designing preventive and control strategies concurrent with the development of the irrigation projects will be required to reduce prevalence of schistosomiasis. [Ethiop.J.Health Dev. 2009;23(1):48-56]
\end{abstract}

\section{Introduction}

Parasitic worms adversely affect the health of humans in many parts of the world. Intestinal parasitic infections continue to be a public health problem globally, particularly among children in the developing countries (1). In many of the developing countries, the most prevalent and important helminths are those of the soiltransmitted nematodes. Chronic gut infection in humans commonly results from nematodes, particularly that of Ascaris lumbricoides, Trichuris trichiura and hookworms (Ancylostoma duodenale and Necator americanus) (2), and the blood flukes, schistosomes (3). Their distribution is influenced by sanitation, population movement, availability of water bodies, etc. For example, higher rates of ascariasis, trichuriasis and hookworm infection were constantly recorded among migrants from populations working in irrigation schemes in the Awash Valley than among nearby nomads or migrant populations employed in rain-fed agriculture in the semiarid Setit Humora area (4). The fact that hookworm, Ascaris and Trichuris larvae and ova require humid environments as in irrigation schemes indicates the role of such schemes in the transmission of these intestinal parasites (5). Lemma (6) also observed that the continuing large-scale agricultural use of rivers, the construction of highways and population movement lead to the spread of schistosomiasis. Various studies have been conducted on all intestinal parasites or only on Schistosoma mansoni infection in Tigray (12, 22 and 23).

It is known that irrigation and the construction of dams with poor sanitary practice results in rapid spread of S. mansoni, since the aqueous environment provides suitable condition for intermediate snail host (7). Worldwide, in all endemic regions, the development of water resource plays an important role in the spread of schistosomiasis. For example, the introduction of irrigated agricultural scheme has been associated with introduction of $S$. mansoni in both upper and middle part of Awash valley (8).

In Ethiopia, the introduction of irrigated agricultural schemes has been shown to be associated with the introduction of $S$. mansoni in both upper and middle part of Awash Valley (8).

Currently, to reduce dependency on rain fed agriculture, construction of dams for irrigation is underway in Ethiopia. Tigray is one of the regions which have started a rural development program by an extensive construction of dams for irrigation. Although there is no national inventory of small dams in Ethiopia, there are more than 70 reservoirs in Tigray (Northern Ethiopia), ranging in reservoir water volume from 50,000 to $4,500,000 \mathrm{~m}^{3}$ ( $\left.25 \& 26\right)$. The majority of the dams are situated near human settlements at an altitude range of 1700-2700m. Dams serve many different purposes for the community, such as domestic and agricultural water supply, irrigation and fish culture. As a potential very negative side-effect, dams may create conducive environment for breeding sites of malaria and schistosomiasis vectors. Although increased economic benefit of expansion of irrigated agriculture is being realized, its public health impact is not fully understood. The present investigation was undertaken to establish the prevalence and intensity of intestinal schistosome and other helminth infections in relation to development of water bodies for irrigation. The information generated in the current study would help to identify new schistosomiasis foci and it can also be used as a baseline 
data for mapping the distribution of schistosomiasis and future reference for designing and evaluating Schistosomiasis control strategies.

\section{Methods}

Central Tigray encompasses ten districts (Weredas) and has 265 primary schools. The population of Central Tigray was 1,132,112 and of this $88.8 \%$ are subsistence farmers (Fig. 1). South Tigray is divided into eight districts and has 256 primary schools. The population of South Tigray was 938,808 , of which $85 \%$ are subsistence farmers.

The study population was primary school children. They were selected because prevalence of infection in schoolage children can be used as an index for assessing community prevalence (9) and they are likely to accept the inconvenience of providing stool specimens.

\section{Sampling and sample size}

Comparing the results of pre-irrigation health data (especially for the recently constructed reservoirs) would have been important to explain the impact but such data are not available in the region. Thus, 10 representative schools were purposely selected from each of Central and South Tigray zones (Fig. 1). The selection comprises 3 schools from longstanding, 2 schools from recently constructed irrigation schemes, 3 schools from nonirrigated, 1 school from urban center with river nearby and 1 school from urban center with no river nearby. Hundred students from each of the 20 schools were selected using systematic sampling by using a random start. The total sample size was 2000 school children. Data collection was undertaken from October 2001 to January 2002.

\section{Parasitological examination}

Students were supplied with a piece of paper to bring about 3gms of faeces. Specimens were collected on-thespot. Teachers and school directors were assisting investigators in collecting the samples. Students who were not able to pass stool during sample collection were advised not to bring their friends stool, but to report that they could not pass stool. Those who reported were substituted by other students. In the field, the 2000 samples were processed by Kato thick smear (10) and transported to Mekelle University for microscopic examination. One slide was prepared for each sample and examined once by well trained expertise. All positive cases were treated. Those with $S$. mansoni were treated with Praziquantel $40 \mathrm{mg} / \mathrm{kg}$ body weight, single dose, while for others with helminthes (A. lumbricoides and $T$. trichiura and hookworm) infections were treated by Mebendazole 100mg BID for three days.
Intensity of infection was estimated from the number of eggs per gram of faeces (epg). Based on egg counts, cutoff values for classification of intensity of infection were used. Intensity of $S$. mansoni is classified into: light infection (1-99epg), moderate (100-399 epg) and heavy (greater than $400 \mathrm{epg}$ ). Similarly, the classification for $A$. lumbricoides is: light infection (1-4999epg), moderate (5000-49999epg) and heavy (greater than 50,000epg). Intensity of $T$. trichiura is: light infection (1-999epg), moderate (1000-9999 epg) and heavy (greater than 10,000epg). Classification of hookworm is: light infection (1-1999epg), moderate (2000-3999 epg) and heavy (greater than 4,000epg) (11). In the result section, only intensity of $S$. mansoni was presented because the intensity in all others was light infection.

\section{Socioeconomic survey}

Data of socioeconomic factors was collected using a structured questionnaire specifically developed for this purpose. All questions were closed-ended in structure. One of the questions was filled by observation. Data was collected by one of the researchers.

\section{Data Analysis}

Data was entered into and were analyzed using SPSS version 10.1 software package.

\section{Results \\ Prevalence}

A total of 1012 male and 988 female school children were examined. Out of these, 571 (295 males and 276 females) were positive for one or more helminths. On the whole, average intestinal helminth infection was $28.6 \%$ (range: 6\% - 92\%). Considering irrigation practices, the overall prevalence of intestinal helminth infection in long-standing irrigation areas was 38.5\% (range: $14-$ 92\%); in the newly introduced irrigation schemes, it was $20.8 \%$ (range: 6-47\%) and in non-irrigated areas, it was $15.7 \%$ (range: 9-26\%). Furthermore, significant difference $(\mathrm{P}<0.00001)$ was observed between prevalence in the urban centers (40.8\% range: $15-88 \%)$ and rural communities (26.1\% range: 9.5-50\%) (Table 1).

Of the 20 schools surveyed, 11 (55\%) were positive for S. mansoni infection. The difference in the overall prevalence of $S$. mansoni infection with respect to irrigation was $17.5 \%$ in irrigated and $5.5 \%$ in nonirrigated areas $(\mathrm{P}<0.0001)$ (Table 3). Further, the prevalence of $S$. mansoni infection was much higher (27\%) in the longstanding irrigated locations than in the recently constructed irrigation schemes $(10.7 \%)$ and $1.8 \%$ in the non-irrigated locations $(\mathrm{P}<0.0001)$ (see Table 2). Similarly, urban centers with water body nearby had a much higher prevalence (15.5\%) than urban centers with no water body nearby $(0.5 \%)$. 
Table 1: Proportion of students positive for one or more intestinal helminth species in South and Central Tigray, 2002

\begin{tabular}{llllllll}
\hline \multirow{2}{*}{ Setting } & \multicolumn{3}{c}{ South Tigray } & & \multicolumn{2}{c}{ Central Tigray } & $\begin{array}{l}\text { Total } \\
\text { (ST \& CT) }\end{array}$ \\
\cline { 2 - 6 } & Male & Female & Total & Male & Female & Total & \\
\hline Long-standing & $74 / 152$ & $76 / 148$ & $150 / 300$ & $40 / 150$ & $41 / 150$ & $81 / 300$ & $231 / 600$ \\
(Rural)dam & $(48.7)$ & $(51.4)$ & $(50)$ & $(26.7)$ & $(27.3)$ & $(27)$ & $(38.5)$ \\
Recent & $6 / 84$ & $13 / 116$ & $19 / 200$ & $37 / 115$ & $27 / 85$ & $64 / 200$ & $83 / 400$ \\
dam (Rural) & $(7.1)$ & $(11.2)$ & $(9.5)$ & $(32.2)$ & $(31.8)$ & $(32)$ & $(20.8)$ \\
No irrigation & $21 / 163$ & $28 / 137$ & $49 / 300$ & $26 / 151$ & $19 / 149$ & $45 / 300$ & $94 / 600$ \\
(Rural) & $(11.5)$ & $(20.4)$ & $(16.3)$ & $(17.2)$ & $(12.8)$ & $(15)$ & $(15.7)$ \\
Urban & $59 / 96$ & $52 / 104$ & $111 / 200$ & $32 / 101$ & $20 / 99$ & $52 / 200$ & $163 / 400$ \\
& $(61.5)$ & $(50)$ & $(55.5)$ & $(31.7)$ & $(20.2)$ & $(26)$ & $(40.8)$ \\
\hline Total & $160 / 495$ & $169 / 505$ & $329 / 1000$ & $135 / 517$ & $107 / 483$ & $242 / 1000$ & $571 / 2000$ \\
(Overall) & $(32.3)$ & $(33.5)$ & $(32.9)$ & $(26.1)$ & $(22.2)$ & $(24.2)$ & $(28.6)$ \\
\hline
\end{tabular}

Key:1= values in brackets are \%; 2 =in $50 \%$ of the urban area studied there are rivers nearby; ST= south Tigray; $\mathrm{CT}=$ Central Tigray

Table 2: S. mansoni distribution in school children with respect to different irrigation practices and sex in South and Central Tigray, 2002

\begin{tabular}{lllllll}
\multirow{2}{*}{ Settings } & \multicolumn{3}{c}{ Male } & \multicolumn{2}{c}{ Female } & \multicolumn{2}{c}{ Total } \\
\cline { 2 - 7 } & No & $\%$ & No & $\%$ & No & $\%$ \\
\hline LSI & $77 / 303$ & 25.5 & $83 / 297$ & 27.9 & $160 / 600$ & 27 \\
$\mathrm{RCI}$ & $27 / 200$ & 13.6 & $16 / 200$ & 8 & $43 / 400$ & 10.7 \\
$\mathrm{NI}$ & $9 / 321$ & 0.7 & $2 / 288$ & 2.3 & $11 / 600$ & 1.8 \\
UW & $17 / 98$ & 11.7 & $14 / 102$ & 13.5 & $31 / 200$ & 15.5 \\
UNW & $1 / 100$ & 1 & $0 / 100$ & 0 & $1 / 200$ & 0.5 \\
\hline
\end{tabular}

Abbreviations: LSI= Long-standing irrigation, $\mathrm{RCl}=$ Recently constructed irrigation, $\mathrm{NI}=$ Non-irrigated area, UW= Urban with water body near by,

UNW= Urban with no water body nearby

Table 3: Primary schools in South and Central Tigray with children positive for S. mansoni infection, 2002

\begin{tabular}{lllcl}
\hline Schools & Altitude & Zone & $\begin{array}{c}\text { \% infection } \mathbf{n = 1 0 0} \\
\text { (in each School) }\end{array}$ & Irrigation Practice \\
\hline Tumuga & 1450 & ST & 87 & Long-standing \\
Meara & 2050 & ST & 19 & Long-standing \\
Gira Bered & 2100 & ST & 2 & Recently constructed dam \\
Dibdibo & 1850 & CT & 41 & Recently constructed dam \\
Adiha & 1600 & CT & 25 & Long-standing \\
Mariam Shewito & 1900 & CT & 23 & Long-standing \\
Agbe & 1550 & CT & 7 & Long-standing \\
Godowa & 2510 & CT & 2 & Non-irrigated \\
Lekia & 1900 & CT & 9 & Urban \\
Abi Adi & 1700 & CT & 32 & Urban \\
Abreha Atsbeha & 2000 & CT & 1 & \\
\hline Abbreviatigated
\end{tabular}

Abbreviations: CT = Central Tigray, ST = South Tigray

The prevalence of $S$. mansoni infection with respect to age showed a peak in the age group 10-14 years old $(15 \%)$ while the rate of infection in 5-9 years old was $8.4 \%$ and that for $15-19$ years old was $11 \%$ (Table 4 ). Unlike in $S$. mansoni infection, the peak infection due to geo-helminths was in the age group 5-9 (14.8\%) and 10$14(14.7 \%)$ and the least affected group was the age group 15-19 (10\%) $(\mathrm{P}<0.03)$. The highest prevalence of geo-helminths (88\%) was in Alamata, a small town in Southern Tigray. 
Table 4: Prevalence of Intestinal Helminth Infections by zone and age in school children in South and Central Tigray, 2002

\begin{tabular}{|c|c|c|c|c|c|c|c|c|c|c|c|c|c|c|c|c|}
\hline \multirow[t]{3}{*}{ Zone } & \multicolumn{16}{|c|}{ Infection by Age } \\
\hline & \multicolumn{8}{|c|}{ S. mansoni } & \multicolumn{8}{|c|}{ Geo-helminth } \\
\hline & \multicolumn{2}{|c|}{$5-9$} & \multicolumn{2}{|c|}{$10-14$} & \multicolumn{2}{|c|}{$15-19$} & \multicolumn{2}{|c|}{ Total } & \multicolumn{2}{|c|}{$5-9$} & \multicolumn{2}{|c|}{$10-14$} & \multicolumn{2}{|c|}{$15-19$} & \multicolumn{2}{|l|}{ Total } \\
\hline $\mathrm{CT}$ & 32 & 10.6 & 79 & 15.7 & 29 & 14.9 & 140 & 14 & 15 & 5 & 16 & 3.2 & 6 & 3.1 & $33 / 1000$ & 3.3 \\
\hline ST & 23 & 6.8 & 81 & 14.5 & 4 & 3.8 & 108 & 10.8 & 80 & 23.7 & 140 & 25.1 & 24 & 23.1 & $244 / 1000$ & 24.4 \\
\hline Total & 55 & 8.6 & 160 & 15.1 & 33 & 11 & 248 & 12.4 & 95 & 14.8 & 156 & 14.7 & 30 & 10 & $277 / 2000$ & 13.9 \\
\hline
\end{tabular}

On the average, the prevalence of $S$. mansoni infections with respect to altitude showed highest prevalence in the lowlands and the least in the highlands $(\mathrm{P}<0.0001)$. Similarly, significantly high $(\mathrm{P}<0.0001)$ prevalence was observed for A. lumbricoides and T. trichiura (result not shown).

It also was evident that $S$. mansoni prevalence was significantly associated with rural areas $(\mathrm{P}<0.03)$, while A. lumbricoides and T. trichiura infections were more prevalent in the urban centers $(\mathrm{P}<0.0001)$ (Table 5).
Information obtained on environmental conditions such as the condition of the floor of the house (cemented or not), availability of toilet and potable water and wearing of shoes by the students showed that none of the conditions were significantly associated with parasite prevalence (Table 6). Only $18.3 \%$ of the students examined had relatively better hygienic living conditions. However, even among these groups, $47.8 \%$ were harboring one or more parasite. The majority of the study subjects belonged to the category \# 4 (Floor not cemented, no toilet and no safe water but wearing shoes) and the group had the highest parasite infection (59.1\%).

Table 5: Prevalence of parasitic infection with respect to altitude, urban and rural in school children in South and Central Tigray, 2002

\begin{tabular}{|c|c|c|c|c|c|c|c|c|c|c|}
\hline \multirow{3}{*}{ Parasite } & \multicolumn{6}{|c|}{ Altitude } & \multirow{2}{*}{\multicolumn{2}{|c|}{ Urban }} & \multirow{2}{*}{\multicolumn{2}{|c|}{ Rural }} \\
\hline & \multicolumn{2}{|c|}{$\begin{array}{r}\text { Highland } \\
>2500 \text { masl } \\
\end{array}$} & \multicolumn{2}{|c|}{$\begin{array}{c}\text { Medium } \\
2000-2500 \text { masl } \\
\end{array}$} & \multicolumn{2}{|c|}{$\begin{array}{l}\text { Lowland } \\
<2000 \text { masl }\end{array}$} & & & & \\
\hline & No & $\%$ & No & $\%$ & No & $\%$ & No & $\%$ & No & $\%$ \\
\hline S. $m$ & 2 & 1 & 21 & 3.5 & 223 & 18.6 & $32 / 400$ & 8 & $214 / 1600$ & 13.8 \\
\hline H. w & 0 & 0 & 3 & 0.5 & 13 & 1.1 & $1 / 400$ & 0.3 & $15 / 1600$ & 0.9 \\
\hline T. $t$ & 1 & 0.5 & 13 & 2.2 & 50 & 4.2 & $34 / 400$ & 8.5 & $30 / 1600$ & 1.9 \\
\hline A. I & 6 & 3 & 17 & 2.8 & 171 & 14.3 & $90 / 400$ & 22.5 & $104 / 1600$ & 6.5 \\
\hline
\end{tabular}

Abbreviations: S.m = S. mansoni, $\mathrm{Hw}=$ Hookworm, A.I = A. lumbricoides, T.t $=$ T. trichiura,

Table 6: Proportion of school children harboring parasites within different socioeconomic and environmental conditions in South and Central Tigray, 2002

\begin{tabular}{|c|c|c|c|c|c|c|c|c|}
\hline \multirow{2}{*}{$\begin{array}{l}\text { Socioeconomic } \\
\text { \& environmen- } \\
\text { tal condition }\end{array}$} & \multicolumn{2}{|c|}{ Alamata } & \multicolumn{2}{|c|}{ Maichew } & \multicolumn{2}{|c|}{ Abyi Adi } & \multicolumn{2}{|c|}{ Total } \\
\hline & $\begin{array}{l}\text { Examin } \\
(\mathrm{n})\end{array}$ & $\begin{array}{l}\text { Positive } \\
\text { n (\%) }\end{array}$ & $\begin{array}{l}\text { Exami } \\
\text { (n) }\end{array}$ & $\begin{array}{l}\text { Positive } \\
\text { n (\%) }\end{array}$ & $\begin{array}{l}\text { Exam } \\
\text { ined }(n)\end{array}$ & $\begin{array}{l}\text { Positive } \\
\text { n (\%) }\end{array}$ & $\begin{array}{l}\text { Examined } \\
\mathrm{n}(\%)\end{array}$ & $\begin{array}{l}\text { Positive } \\
\text { n (\%) }\end{array}$ \\
\hline Category 1 & 20 & $15(75)$ & 4 & $1(25)$ & 22 & $6(27.3)$ & $46(18.25)$ & $22(47.82)$ \\
\hline Category 2 & 1 & $1(100)$ & 0 & 0 & 13 & $5(38.5)$ & $14(5.56)$ & $6(42.86)$ \\
\hline Category 3 & 16 & $14(87.5)$ & 23 & $4(17.4)$ & 3 & 0 & 42 (16.67) & $18(42.86)$ \\
\hline Category 4 & 35 & $31(88.6)$ & 12 & $5(41.7)$ & 46 & $19(41.3)$ & $93(36.9)$ & 55 (59.14) \\
\hline Category 5 & 10 & $9(90)$ & 12 & $2(16.7)$ & 6 & $2(33.3)$ & $28(11.11)$ & $13(46.13)$ \\
\hline Category 6 & 15 & $15(100)$ & 0 & 0 & 10 & $5(50)$ & $25(9.92)$ & $20(80)$ \\
\hline Category 7 & 3 & $3(100)$ & 1 & $1(100)$ & 0 & 0 & $4(1.59)$ & $4(100)$ \\
\hline Total & 100 & 88 & 52 & $13(25)$ & 100 & 37 & 252 & $138(54.76)$ \\
\hline
\end{tabular}

Key: 1= Floor cement, shoe wearing, use toilet \& potable water, 2= Floor cement, shoe wearing, no toilet \& no potable water, 3= Floor not cemented, shoe wearing, use toilet \& potable water, 4= Floor not cemented, shoe wearing,

no toilet $\&$ no potable water, $5=$ Floor not cemented, shoe wearing, no toilet $\&$ no potable water $6=$ Floor not cemented, not shoe wearing, no toilet but use potable water, and $7=$ Floor not cemented, not shoe wearing, no toilet $\&$ no potable water 


\section{Intensity of $S$. mansoni infection}

The highest intensity of $S$. mansoni infection was in the irrigated sites followed by urban centers with nearby water bodies. Newly introduced irrigation projects were the next in intensity while the least intensity was in non- irrigated and urban centers with no nearby water body (P $<0.0001$ ) (Fig. 2). The overall data for both zones revealed that the peak prevalence for heavy $S$. mansoni infection was in the age group 10-14 (7.5\%) followed by 15-19 (6.1\%) and 5-9 1(0.3\%) (P< 0.003) (Fig. 3a).

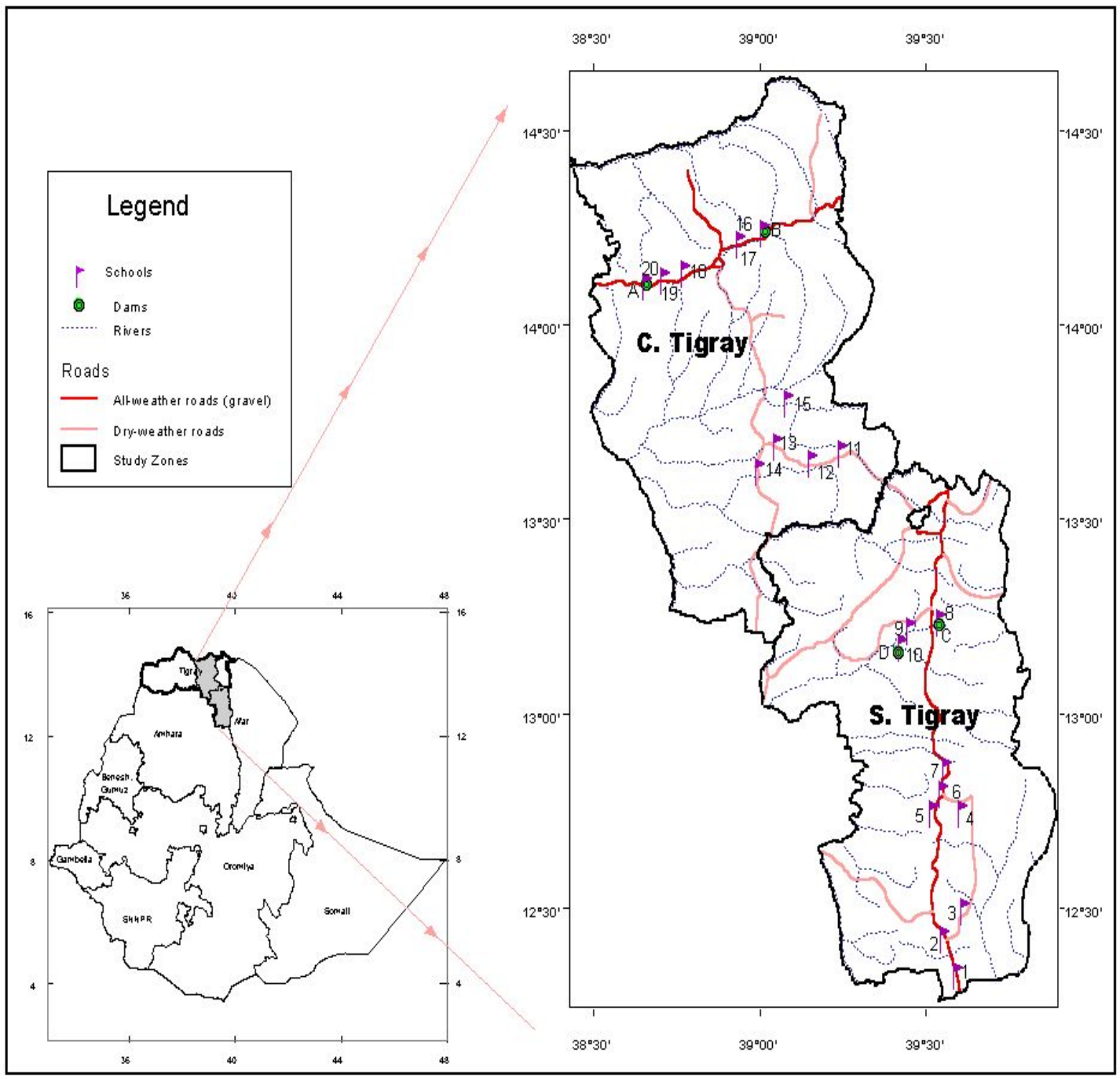

Figure 1: Map of the Study Area

\section{Key: Primary Schools}

\section{South Tigray}
1) Tumuga
2) Adget Fana (Alamata)
3) Gerjelle
4) Genettie
5) Mekan
6) Hizba (Maichew)
7) Birhan Lekatit
8) Ara
9) Meara
10) Gira Bered
11) Central Tigray

12) Aynimbirkekiy

13) Godewa

14) Agbe

15) Abyi Adi

16) Adiha

17) Dibdibo

18) Mariam Shewito

19) Leki'a

20) Abreha Atsbeha (Axum)

21) Dura
Dams: A) May Nugus (Dura)
B) Dibdibo
C) Gum Selasa (Ara)
D) Adi Kenafiz (Gira Bered) 


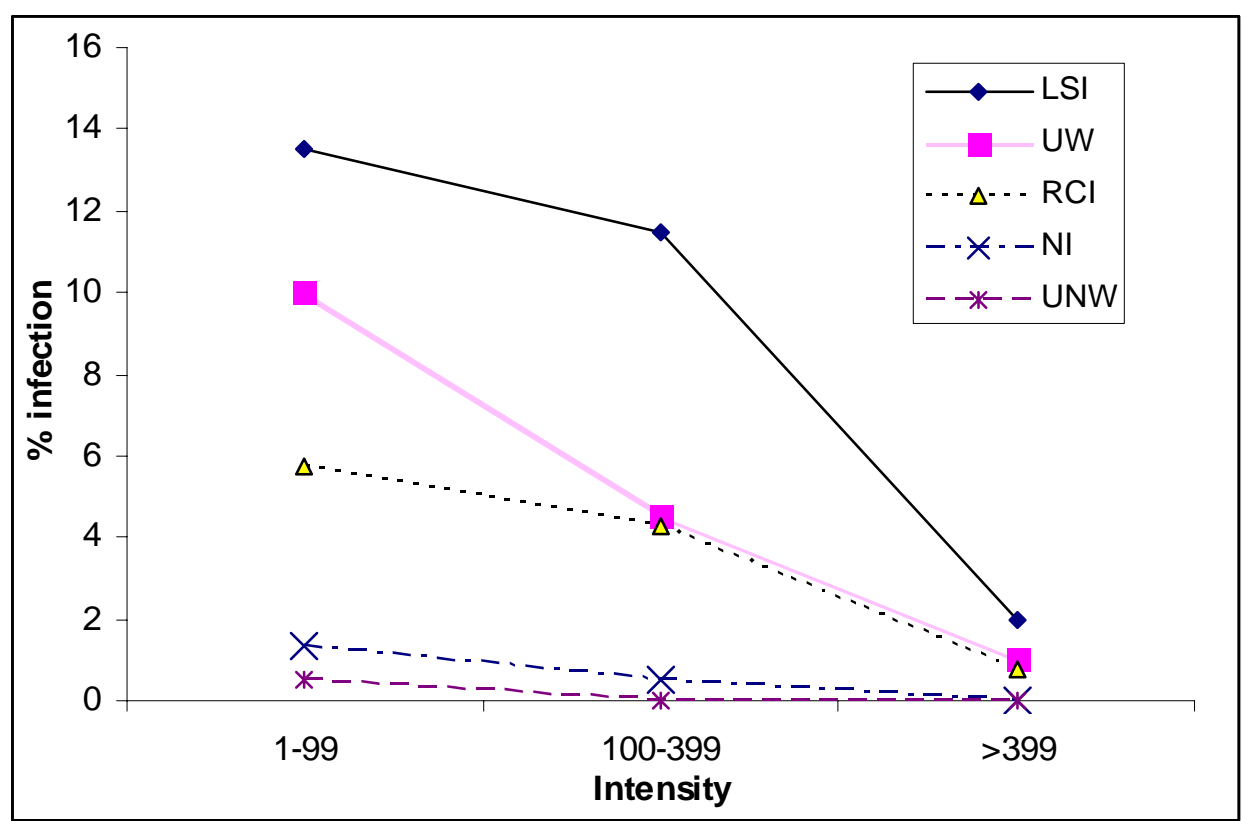

Figure 2: Prevalence of $S$. mansoni infection shown by intensity levels

Key: Light infection = 1-99epg, Moderate infection = 100-399epg and Heavy infection $=>$ 399epg, LSI = Long-standing irrigation, $\mathrm{RCI}=$ Recently constructed irrigation, $\mathrm{NI}=$ Non-irrigated area, $(\mathrm{UW})=$ urban with water body nearby, (UNW) $=$ Urban with no water body nearby

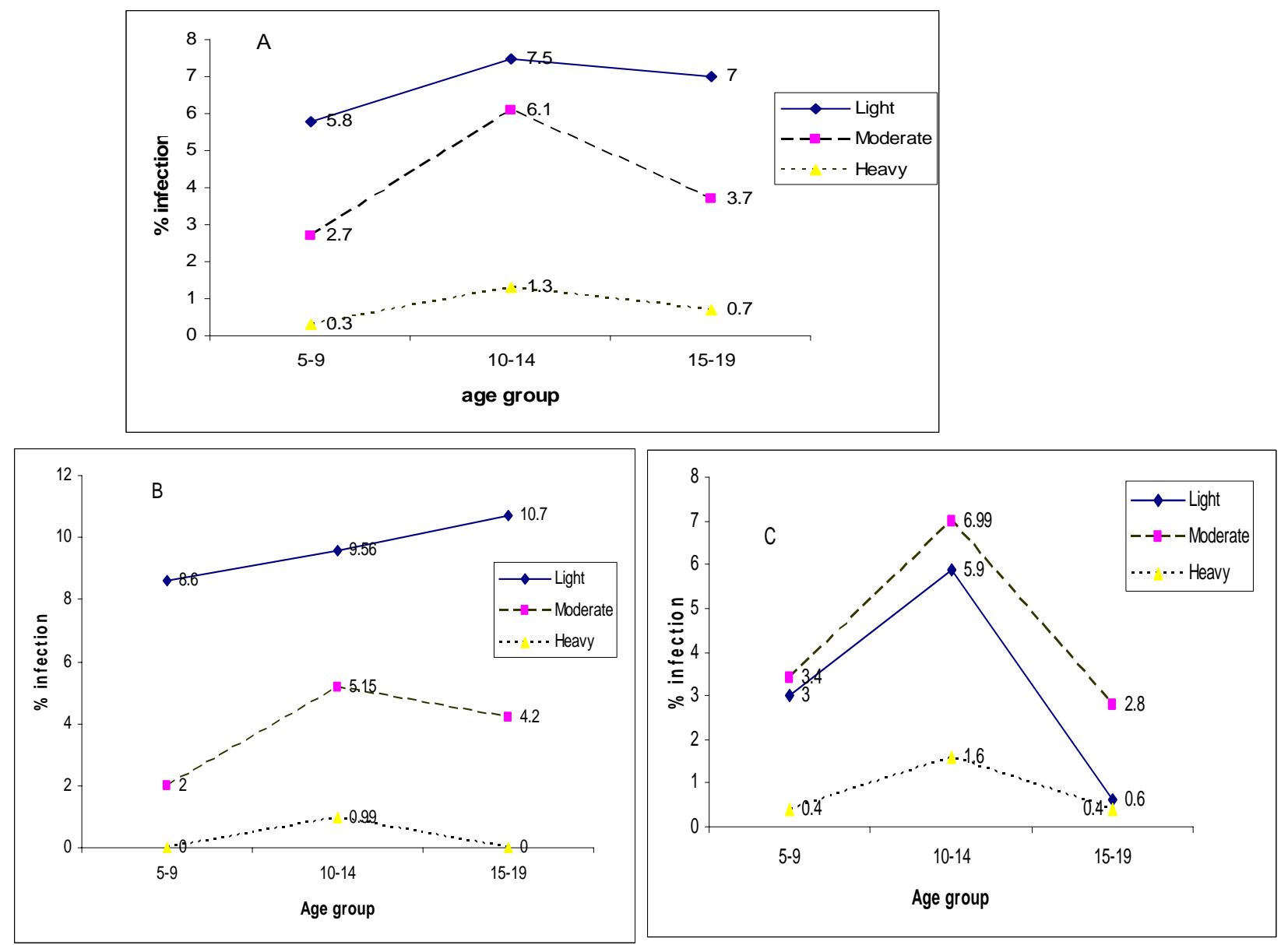

Figure 3: Prevalence of S. mansoni infection shown by intensity levels and age

Key: Light infection = 1-99epg, Moderate infection = 100-300epg and Heavy infection = >399epg, $(A)=$ Overall, (B) = Central Tigray, $(C)=$ South Tigray 



\section{Discussion}

The overall prevalence of intestinal helminthic infections in rural and urban centers that have water bodies nearby is a reflection of the high $S$. mansoni prevalence in areas with water and the prevailing favorable condition of moist and warm temperature for geo-helminths in the study sites. The finding that geo-helminth infections are more prevalent in the age groups 5-9 and 10-14 years in both study areas, ST and CT, is an indication that younger children are more exposed since they usually play in the open fields and eat food without washing hands. Thus, as age increases the prevalence of geohelminth infection decreases possibly due to improved personal hygiene and reduced contact with soil. These findings are in agreement with that reported by (12) from Tigray.

In spite of the fact that South and Central Tigray have similar climatic conditions and other factors such as occupation, agricultural practices, human waste disposal and food habits, the finding that geo-helminth infection prevalence was significantly higher in South Tigray than in Central Tigray may be explained by the contribution of highest prevalence in Alamata in South Tigray. In Alamata, most plantations around human residences are frequently watered creating moist condition in an environment of hot temperature, thus making conditions for preservation of infective helminth eggs favorable.

Contrary to the report of a study elsewhere (13), the prevalence of $A$. lumbricoides and $T$. trichiura, was significantly higher in the urban than in the rural settings. These findings are consistent with that in Kombolcha town (South Wollo) (14) and Addis Ababa and Debre Zeit (15). This may be attributed to the high population density and the poor sanitation prevailing in the urban centers.

The high prevalence of the major nematode parasites and $S$. mansoni in the lower altitudes can be accounted for by the relatively high temperature and moisture conditions favorable for larval development.

Lack of difference in parasite prevalence among students that do and do not have access to safe water, latrines, cemented floor and shoes or not being in the urban residences, implies that to reduce worm burden in a community, the quality of the socioeconomic indicators and their accessibility to the population must be much higher than what was determined in this study.

The pattern of schistosomiasis prevalence in Tigray where it was highest in the longstanding irrigated areas followed by the urban communities with water nearby, and next in the recently constructed irrigated sites followed by the non-irrigated sites, and in urban communities with no water nearby was similar to that reported from Methara Sugar State in Estern Shoa (16).
The high prevalence of $S$. mansoni infection in older dams, when compared with new dams less than 5 years old in an earlier study in Tigray (12) was confirmed by our study. This may be explained by the fact that adequate period of time is necessary for the establishment of schistosomiasis endemicity in a locality. Our finding has shown that the condition for established schistosomiasis endemicity has been fulfilled in the irrigation schemes in Tigray and hence, the danger of irrigation projects creating an ideal environment for the introduction and spread of the infection is real.

The situation in Gerjelle, which is an area with longstanding irrigation practices but with no S. mansoni positive individuals among the school children was an exception. The more likely means of spreading snails in irrigation schemes is by canal intake water flow from streams and rivers. Besides, it is often suggested that aquatic organisms can be introduced into new water bodies by water birds that can carry resting eggs as they fly from one water body to the other (24). Thus, we cannot say it is risk free because the snail intermediate hosts can be introduced into new water bodies by these birds.

The source of parasites could be infected persons that visit from endemic nearby foci.

The peak prevalence and intensity registered for $S$. mansoni infection in the age group 10-14 followed by the age group 15-19 years and, the lowest in the age group 59 , was in agreement with earlier reports different parts of Ethiopia (17,18), including Tigray (12). The low infection rate in the age group 5-9 years might be attributed to the low water contact behavior of children of this age.

The significantly higher prevalence of S. mansoni in the rural than in the urban communities can be accounted for by the availability of more water bodies in the rural areas where irrigation schemes are present. The relationship between intensity of schistosomiasis infection and proximity of the location to water bodies has been reported from other locations in Ethiopia (13).

Our study has presented evidence for the endemicity of schistosomiasis mansoni in five localities (Adiha, Tumuga, Diobdibo, Lekia and Mariam Shewito) that have not been reported before. It is only Dibdibo (with $41 \%$ prevalence) dam, which is located near Dibdibo Primary School, that is among the recently constructed dams, while the other schools were among the longstanding irrigation users. This shows the need for careful surveys of an area for schistosomiasis endemicity before considering it free of the disease.

Longitudinal studies had indicated that prevalence of schistosome infection increases with the age of the irrigated area. In Ethiopia this was documented in

Ethiop.J.Health Dev. 2009;23(1) 
Methara (19, 16) and Wonji-Shoa Sugar Estates (20). Studies from Egypt had also shown an increased prevalence from $0.05 \%$ to $60 \%$ within less than five years following introduction of an irrigation scheme into a region (21).

Thus, the increased prevalence rate of $S$. mansoni infection with the increased introduction of irrigation schemes will be of great public health concern unless appropriate control measures are designed. It is possible, with increased development of irrigation, schistosomiasis might further increase in prevalence and intensity in the near future. Therefore, designing schistosomiasis prevention and control strategies concurrent with the development of the irrigation projects will be required to limit the spread of schistosomiasis.

Periodic de-warming of school children and, if possible, the whole community, is recommended. To further reduce the overall worm burden, construction of latrines and supply of safe water, inculcation of proper behavior in the proper use of the available facilities through education are necessary.

\section{Acknowledgement}

We would like to acknowledge Addis Ababa University for financial support and Mekelle University for transport services during the fieldwork. We wish also to extend our gratitude to school directors and students of the study area for their cooperation.

\section{References}

1. World Health Organization, Intestinal protozoa and helminth infection. WHO Tech.Rep.Ser.666. Geneva. 1981.

2. World Health Organization. Prevention and control of schistosomiasis and soil transmitted helminthiasis. WHO Tech. Rep. Ser. No. 912, WHO, Geneva, Switzerland 2002.

3. Rozendaal, J .R. Vector Control Methods for use by Individuals and Communities. Geneva, WHO 1997; 337- 356.

4. Kloos, H., Lemma, A., Kibru, B., Gebre, A., Mazengia, B., Feleke, G. and DeSole, G. Intestinal Parasitism in migrant farm labour populations in irrigation schemes in the Awash Valley, Ethiopia, and in major labour source areas. Ethiop. Med .J. 1980; 18: 52-61.

5. Kloos, H., DeSole, G. and Lemma, A. Intestinal Parasitism in semi-nomadic pastoralists and subsistence farmers in and around irrigation schemes in the Awash Valley, Ethiopia, with especial emphasis on ecological and cultural associations. Soc. Sci. Med. 1981;15: 457 - 469.

6. Lemma, A Bilhariasis in Awash Valley. I. An Epidemiological study with special emphasis on its possible future economic and public health importance. Ethiop. Med. J.1969;7:147-176.
7. Markell. E.K. and Voge, M. Medical Parasitology. ${ }^{\text {rd }}$ Ed. W.B. Sounders Company. Philadelphia London. Toronto. 1971:171-173.

8. Lo,C.T., Kloos,H, and Hailu, B. Schistosomiasis. In: The Ecology of Health and Disease in Ethiopia, Zein Ahmed and Kloos, H. (editors). Addis Ababa: EMPDA Press, pp. 1988;196- 207.

9. Guyatt, H.L,Brooker,s. and Donnelly,CA. Can prevalence of infection in school aged children be used as an index for assessing community prevalence? Parasitology 1999;118: 257-268.

10. Peters, P.A., Alamy, M.E., Warren, K.S. and Mahmoud, A.A.F. Quick Kato Smear for field quantification of Schistosoma mansoni eggs. Am. J. Trop. Med. Hyg., 1980;29 (2):217- 219.

11. Montresor, A., Gyorkos, T. W., Crompton, D. W. T., Bondy, D. A. P. and Savioli, L. Monitoring helminth control programs. Guideline for monitoring the impact of control programs aimed at reducing morbidity caused by soil-transmitted helminthes and schistosomes, with particular reference to school age of children. WHO/ CDS / CPC / SIP/99.3. Geneva, WHO. 1999.

12. Alemayehu, T., Ye-ebiyo, Y., Ghebreyesus, T. A. and Wtten, K. H. Malaria, Schistosomiasis, and intestinal helminths in relation to micro-dams in Tigray, northern Ethiopia. Parassitologia, 1998;40: 259-267.

13. Jemaneh, L. Intestinal helminth infections in school children in Gonder Town and surrounding areas, northwest Ethiopia. SIENT: Ethiop. J. Sci. 1999;22:209-220.

14. Assefa, T., Weldemicheal, T. Dejenie, A. Intestinal Parasitism among students in three localities in South Wollo, Ethiopia. Ethiop. J. Health Dev. 1998;12:231-235.

15. Lemma, A Parasitological Survey of Addis Ababa and Debrezeiet school children, with special emphasis on bilharziasis. Ethiop. Med. J. 1968;6:6171.

16. Abebe, F., Tedla, S., Birrie, H. and Medhin, G. Transmission dynamics of $S$. mansoni in an irrigation setting in Ethiopia. Ethiop. J. Health Dev.1995;9:147-156.

17. Erko, B., Tedla, S. and Petros, B. Transmission of intestinal schistosomiasis in Bahr Dar, Northwest, Ethiopia. Ethiop Med. J. 1991;29:199-211.

18. Birrie, H., Medhin, G., Erko, B., Beshah, G. and Gemechu, T. Intestinal helminth infections among the current residents of the future Finchaa Sugar Plantation area, Western Ethiopia. Ethiop. J. Health Dev. 1997;11:219-228.

19. Kloos, H. Water resource development and schistosoma ecology in the Awash Vally, Ethiopia. Soc. Sci. Med. 1985;20:609-625.

20. Tedla, S. and Yimam, M. Schistosomiasis at the Wongi-Shoa Sugar Estate during two decades (19641985). Afr. J. Sci. Tech.; 1986;1:1-18. 
21. Farid, M. A. The Aswan High Dam Development Project: In: Man made lakes and human health, Stanley, N. F. and Algers, M. P. (eds). Academic Press, London, New York, San Francisco, Toronto, 1971 Pp:345-362.

22. Birrie, H., Weldemichael, T., Redda, A. and Chane, T. The status of $S$. mansoni and snail hosts in Tigray and northern Wollo regions, northern Ethiopia. Ethiop Med J. 1994;32:245-254.

23. Woldemichael, T. and Kebede, A. Newly identified endemic areas of schistosomiasis mansoni in Tigray, north Ethiopia. Ethiop. Med. J. 1996;34:73-81.

24. Figuerola, J. and Green, A. J. Dispersal of aquatic organisms by water birds: a review of past research and priorities for future studies. Freshwater Biology, 2002;47:483-494.
25. De Wit, J. Stuwmeren in Tigray (Noord-Ethiopië): kenmerken, sedimentatie en sedimentbronnen. M.Sc. thesis, 2003, Department of Geography, K.U. Leuven.

26. Tadesse Dejenie, Tsehaye Asmelash, L. De Meester, Afework Mulugeta, Abreha Gebrekidan, S. Risch, A. Pals, K. Van der Gucht, W. Vyverman, J. Nyssen, S. Deckers \& S. Declerck, (in press). Limnological and ecological characteristics of tropical semi-arid highland reservoirs in Tigray, Northern Ethiopia. Hydrobiologia, 2008;610:193-209. 